\title{
Difference between the North Atlantic and Pacific meridional overturning circulation in response to the uplift of the Tibetan Plateau
}

\author{
Baohuang Su ${ }^{1,4}$, Dabang Jiang ${ }^{1,2,3,4}$, Ran Zhang ${ }^{1}$, Pierre Sepulchre ${ }^{5}$, and Gilles Ramstein ${ }^{5}$ \\ ${ }^{1}$ Institute of Atmospheric Physics, Chinese Academy of Sciences, Beijing 100029, China \\ ${ }^{2}$ Joint Laboratory for Climate and Environmental Change at Chengdu University of Information Technology, \\ Chengdu 610225, China \\ ${ }^{3}$ CAS Center for Excellence in Tibetan Plateau Earth Sciences, Beijing 100101, China \\ ${ }^{4}$ University of Chinese Academy of Sciences, Beijing 100049, China \\ ${ }^{5}$ Laboratoire des Sciences du Climatet de l'Environnement/IPSL, CEA-CNRS-UVSQ, UMR8212, \\ Orme des Merisiers, CE Saclay, 91191 Gif-sur-Yvette CEDEX, France
}

Correspondence: Dabang Jiang (jiangdb@mail.iap.ac.cn)

Received: 30 August 2017 - Discussion started: 12 October 2017

Revised: 8 April 2018 - Accepted: 4 May 2018 - Published: 8 June 2018

\begin{abstract}
The role of the Tibetan Plateau (TP) in maintaining the large-scale overturning circulation in the Atlantic and Pacific is investigated using a coupled atmosphere-ocean model. For the present day with a realistic topography, model simulation shows a strong Atlantic meridional overturning circulation (AMOC) but a near absence of the Pacific meridional overturning circulation (PMOC), which are in good agreement with the present observations. In contrast, the simulation without the TP depicts a collapsed AMOC and a strong PMOC that dominates deep-water formation. The switch in deep-water formation between the two basins results from changes in the large-scale atmospheric circulation and atmosphere-ocean feedback over the Atlantic and Pacific. The intensified westerly winds and increased freshwater flux over the North Atlantic cause an initial slowdown of the AMOC, while the weakened East Asian monsoon circulation and associated decreased freshwater flux over the North Pacific give rise to the initial intensification of the PMOC. The further decreased heat flux and the associated increase in sea-ice fraction promote the final AMOC collapse over the Atlantic, while the further increased heat flux leads to the final PMOC establishment over the Pacific. Although the simulations were performed in a cold world, it still importantly implicates that the uplift of the TP alone could have been a potential driver for the reorganization of PMOCAMOC between the late Eocene and early Oligocene.
\end{abstract}

\section{Introduction}

The uplift of the Tibetan Plateau (TP) was a major tectonic event that had occurred throughout the Cenozoic, and its gradual growth had exerted a strong influence on the atmospheric circulation and climate (Molnar et al., 2010). Since the pioneering work of Bolin (1950), the impacts of mountain uplift on regional and global climate have been extensively investigated. Nevertheless, most studies have emphasized the role of mountain ranges on atmosphere dynamics, while quantifications of the associated impact on ocean dynamics have been rare. For example, most previous works have used atmospheric general circulation models to address regional climate effects, notably the Asian monsoon and arid environment evolutions (e.g., Ruddiman and Kutzbach, 1989; Ramstein et al., 1997; An et al., 2001; Liu and Yin, 2002; Jiang et al., 2008; Zhang et al., 2015). However, simulations have recently been applied to investigate the effect of mountain uplift in the context of the atmosphere-ocean system, and a few studies have proposed that the uplift of the Andes (Sepulchre et al., 2009) and Rocky Mountains (Seager et al., 2002) is closely linked to the evolution of oceanic circulations, including the Gulf Stream and Humboldt Current, and the El Niño-Southern Oscillation system (Feng and Poulsen, 2014). Although it has been indicated that the TP uplift affects sea surface temperatures, sea surface salinity, 
precipitation, and trade winds for both the Pacific and equatorial Indian Ocean (Abe et al., 2003; Kitoh, 2004; Okajima and Xie, 2007), the influence of the TP uplift on the highlatitude oceanic circulations, particularly in the North Atlantic, has rarely been explored.

The potential importance of mountain uplift in modifying the oceanic thermohaline circulation has previously been investigated. Ruddiman and Kutzbach (1989) indicated that mountain-uplift-induced changes in the North Atlantic surface circulation are expected to increase the North Atlantic Deep Water formation. In addition, Rind et al. (1997) performed the coupled model simulations with and without the TP and proposed that the TP may have a considerable impact on the large-scale meridional overturning circulation (MOC). However, the integration time used in these pioneering simulations was too short to fully evaluate the deep oceanic circulation response, and thus more studies are still needed to evaluate the possible role of the TP in modulating the MOC.

On a geological timescale, remarkable reorganization and evolution of the large-scale oceanic overturning circulation, from the Southern Ocean deep-water dominating mode to the modern-like North Atlantic deep-water mode, have been evidenced through the late Eocene to the early Oligocene (Wright and Miller, 1993; Davies et al., 2001; Via and Thomas, 2006). This dramatic shift is possibly associated with major rearrangements in the ocean seaways and other tectonic changes, although the ultimate trigger is still being debated (Zhang et al., 2011). In addition, it is suggested that the regional surface of the TP had reached a high elevation of more than $4000 \mathrm{~m}$ around $40 \mathrm{Myr}$ ago (Dupont-Nivet et al., 2008; Wang et al., 2008), although debates regarding paleoaltitude reconstructions remain (Botsyun et al., 2016). Given this timing of TP uplift, it is important to quantify the contribution of TP uplift on the meridional oceanic circulation of the Northern Hemisphere. In this study, therefore, two coupled atmosphere-ocean numerical integrations, with and without the TP, are designed to investigate the role of the TP on the Atlantic MOC (AMOC) and Pacific MOC (PMOC).

\section{Model, experimental design, and density flux analysis}

\subsection{Model and experiments}

The Community Earth System Model (CESM) version 1.0.5 of the National Center for Atmospheric Research is a widely used, well-validated coupled model with dynamic atmosphere, land, ocean, and sea-ice components (Gent et al., 2011). It is applied to this study at a low-resolution configuration that is computationally efficient and well described (Shields et al., 2012) and employs an atmospheric horizontal grid of roughly $3.75^{\circ} \times 3.75^{\circ}$ (T31) with 26 vertical levels. The ocean model adopts a finer oceanic horizontal grid, with a nominal $3^{\circ}$ resolution increasing to $1^{\circ}$ near the Equator $(116 \times 100$ grid points, latitude by longitude $)$ and 60 unevenly spaced layers in the vertical direction. The seaice and land models share the same horizontal grids as the ocean and atmosphere models, respectively, where the seaice component is a dynamic-thermodynamic model that includes a subgrid-scale ice thickness distribution and energyconserving thermodynamics (Holland et al., 2012).

Two experiments are conducted; firstly, a control run with the modern topography (MTP, Fig. 1a), and secondly a sensitivity run in which topography within the region of $20-60^{\circ} \mathrm{N}$ and $60-140^{\circ} \mathrm{E}$ at altitudes higher than $200 \mathrm{~m}$ is set to $200 \mathrm{~m}$ (NTP, Fig. 1b), which enables examination of the climate effect in relation to the TP topography. This TP uplift configuration has been referred to in the majority of previous simulation works (e.g., Liu and Yin, 2002; Jiang et al., 2008). This greatly simplified topographic setting is not intended to represent a realistic scenario constrained by geological evidence and instead represents two end-members of the potential growth histories of the TP. Thus, it is important to note that these experiments only aim to investigate the TP uplift occurring in "a cold world" with an atmospheric $\mathrm{CO}_{2}$ corresponding to the preindustrial values $(284.0 \mathrm{ppm})$. With the exception of topography, all the other boundaries, such as land-sea distribution and orbital parameters, are prescribed to preindustrial conditions. The MTP run is continually integrated for 1100 years, and the NTP run is additionally integrated for another 1840 years starting from the year 1100 of the MTP run. Global mean surface air temperature and sea temperature at a depth of $1000 \mathrm{~m}$ are shown in Fig. 1c. Both simulations reach equilibrium states after more than 1000 model years of integration time, and the final 200 years of both cases are applied for our climate state analysis.

\subsection{Density flux analysis}

Because the major aim of this paper is to analyze changes in the meridional oceanic circulation, we decided to focus on the density flux parameter, which is appropriate to diagnose these oceanic circulation changes. The dense deepwater masses are formed in the area with relatively high surface density achieved by cooling or increasing salinity. To better understand which processes dominated the MOC changes in simulations, it is instructive to further analyze the time evolution of density flux budget. Therefore, a density flux analysis method, in which the total density flux decomposes into the haline contribution due to freshwater flux and the thermal contribution due to heat flux (Schmitt et al., 1989), is adopted in our study. The total density flux is calculated from a linearized state equation of seawater as

$$
F_{\rho}=-\alpha \cdot \frac{Q}{C_{\mathrm{p}}}+\rho(0, T) \cdot \beta \cdot \frac{(E-P-R-I) \cdot S}{1-S} .
$$

$F_{\rho}$ is the total density flux, $-\alpha \cdot \frac{Q}{C_{\mathrm{p}}}$ is the thermal density flux, and $\rho(0, T) \cdot \beta \cdot \frac{(E-P-R-I) \cdot S}{1-S}$ is the haline density term. $C_{\mathrm{p}}$, $T$, and $S$ are the specific heat capacity, surface temperature, 


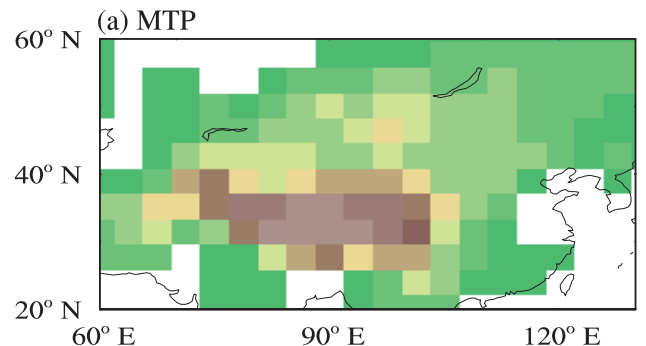

(c) SAT and temperature at $1000 \mathrm{~m}$
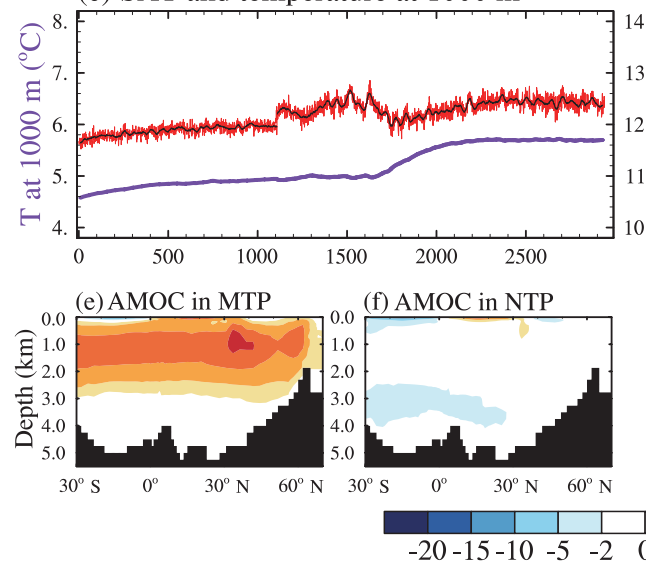

(b) NTP

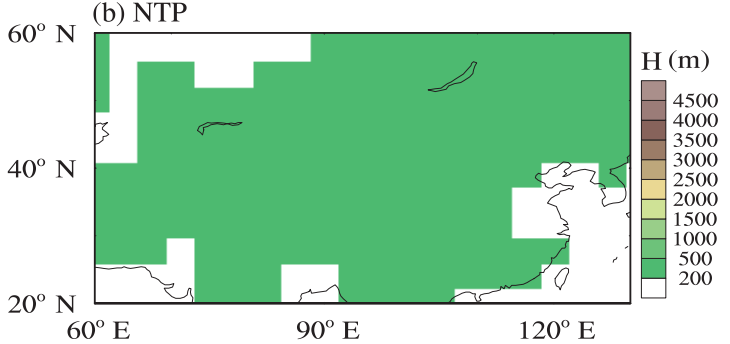

(d) PMOC and AMOC indices
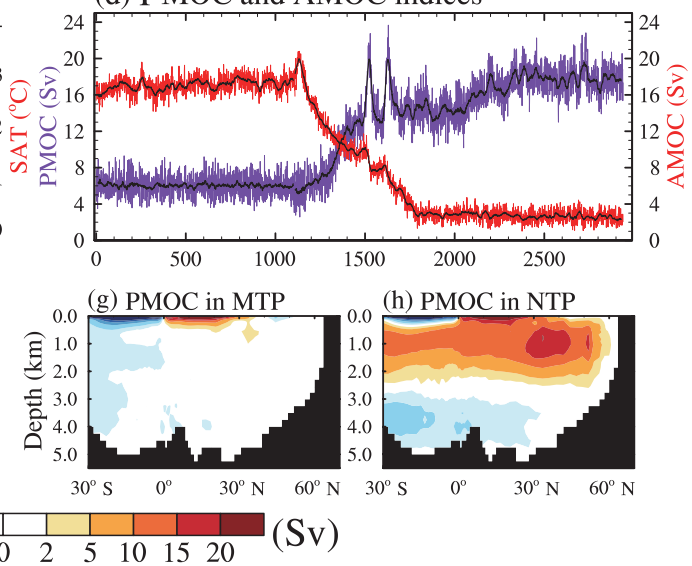

Figure 1. Two topographic height configurations used in experiments: (a) MTP and (b) NTP. (c) Time series of global mean annual $2 \mathrm{~m}$ surface air temperature (SAT) and sea temperature at $1000 \mathrm{~m}$ depth in the MTP (1-1100 years) and NTP (1101-2940 years) simulations; bold black lines show the 21-year running mean. (d) Same as (c) but for PMOC and AMOC indices. AMOC and PMOC indices are defined as the annual maximum of the meridional stream function value north of $28^{\circ} \mathrm{N}$ and below the depth of $500 \mathrm{~m}$ over the North Atlantic and Pacific, respectively. (e-h) Climatological annual mean Atlantic and Indian-Pacific meridional overturning stream function in MTP (e, g) and NTP (f, h); positive (negative) shading represents clockwise (counterclockwise) circulations.

and salinity of seawater, respectively. $\alpha$ and $\beta$ are the thermal expansion and haline contraction coefficients, respectively. $\rho(0, T)$ is the density of freshwater with a salinity of $0 \mathrm{psu}$ and temperature of $T . Q$ represents the net surface heat flux. $E, P, R$, and $I$ denote the freshwater fluxes due to evaporation, precipitation, river runoff, and sea-ice melting (or brine rejection), respectively.

\section{Results}

\subsection{Changes in $\mathrm{AMOC}$ and PMOC}

There are evident changes in the AMOC and PMOC indices in response to the TP uplift (Fig. 1d). With MTP, the AMOC stabilizes at around $17 \mathrm{~Sv}\left(\mathrm{~Sv}=10^{6} \mathrm{~m}^{3} \mathrm{~s}^{-1}\right)$ for more than 1000 years (Fig. 1d, 1-1100 years, red line), which agrees with the observation of $18.7 \pm 5.6 \mathrm{~Sv}$ for 2004-2005 (Cunningham et al., 2007), but with NTP there is a continual weakening of the AMOC until the point of quasi-collapse (ca. 2 Sv; Fig. 1d). In contrast, the PMOC of NTP begins at a sluggish level from MTP (Fig. 1d, 1-1100 years, purple line) and takes as long as 1200 years to reach an equilibrium state that is comparable to the level of the AMOC in MTP (ca. 18 Sv; Fig. 1d, 1101-2940 years, purple line). In agreement with the dramatic responses of AMOC and PMOC, sea surface salinity increases in the North Pacific but decreases in a broad area of the North Atlantic (Fig. 2b). To fully understand the different behaviors between AMOC and PMOC in NTP, in the following sections we further analyze changes in the atmospheric and oceanic circulations and the atmosphere-ocean feedbacks.

\subsection{Atmospheric responses}

The modified AMOC and PMOC are linked to the large-scale atmospheric circulation changes. In terms of model results of the NTP run relative to the MTP run, the surface air temperature over and around the TP and in the North Pacific increased but decreased over the North Atlantic (Fig. 2a), which agrees with the previous simulations (Broccoli and Manabe, 1992; Kutzbach et al., 1993). In addition, there are intensified westerlies over the North Atlantic and weakened subtropical anticyclones and trade winds over the North Pacific (Fig. 2c); the former results from a significant increase in the meridional pressure gradient driven by a large-scale equatorward shift of air mass occupying the current position 

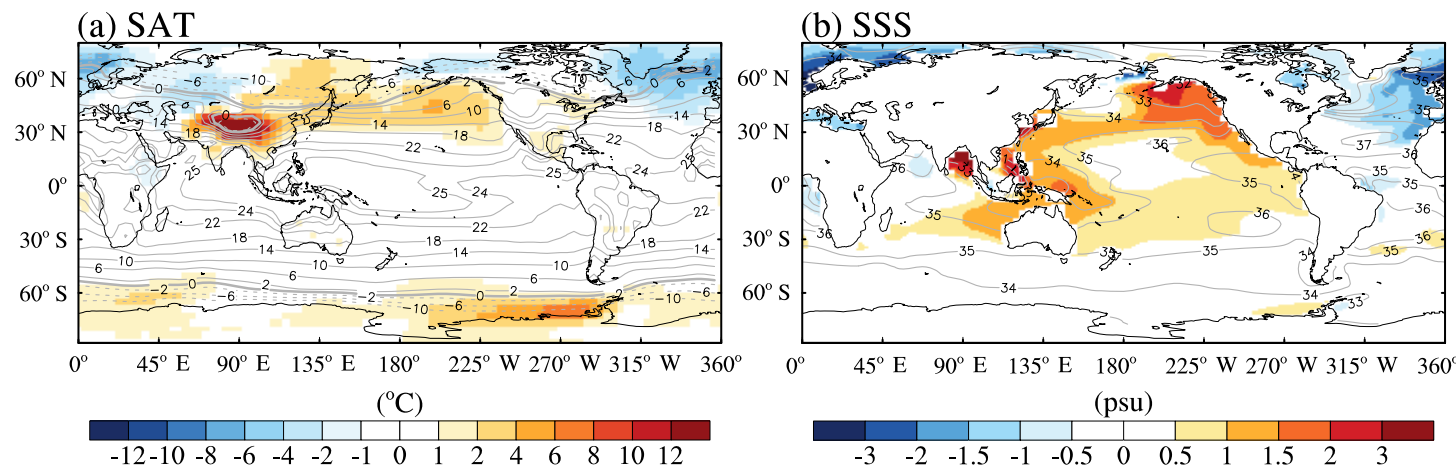

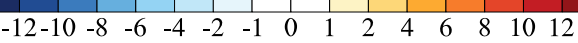

(c) SLP and surface wind

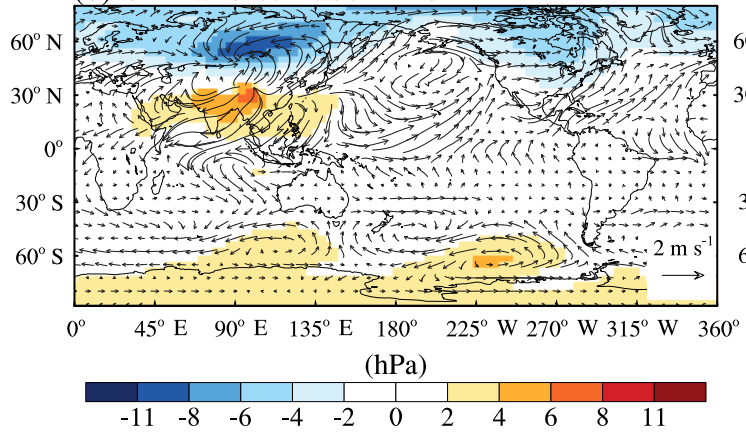

(d) Water vapour flux and divergence

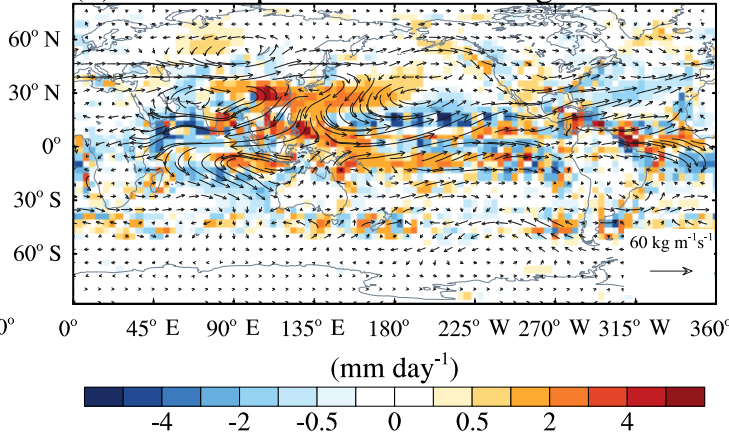

Figure 2. (a) Climatological SAT in MTP (contour) and anomalies (shaded) for NTP minus MTP; (b) same as (a) but for sea surface salinity (SSS); (c) changes in sea-level pressure (SLP, shading) and surface wind (vectors); and (d) vertically integrated (surface to $300 \mathrm{hPa}$ pressure layer) water vapor flux (vectors) and its convergence (shading) in NTP relative to MTP. Unit of convergence is converted to millimeters per day assuming the density of liquid water as $1 \mathrm{~g} \mathrm{~cm}^{-3}$.

of the TP (Fig. 2c) and from a reduced drag of the orographically induced gravity waves associated with the absence of the TP (Palmer et al., 1986; Sinha et al., 2012), while the latter is derived from the weakening of zonal Eurasia-Pacific thermal contrast in the middle troposphere (not shown), especially in boreal summertime, in relation to removal of the mountains (Ruddiman and Kutzbach, 1989; Rodwell and Hoskins, 2001; Kitoh, 2004).

When the TP is removed, the atmospheric moisture transport between the Pacific and Atlantic oceans undergoes a basin-basin asymmetric redistribution as a response to the large-scale circulation anomalies (Fig. 2c). In comparison with MTP results, the NTP simulation shows large amounts of anomalous westerly moisture flux transported through the lowlands of Central America to the North Atlantic, causing weak moisture convergence therein (Fig. 2d). In addition, removal of the TP leads to a significant divergence of moisture over East Asia and the western North Pacific marginal seas (Fig. 2d), which is linked to a weakened monsoon circulation and is consistent with the previous simulations using both atmospheric and coupled ocean-atmosphere general circulation models (Liu and Yin, 2002; Kitoh, 2004; Molnar et al., 2010). The anomalies of atmospheric circulation shown above are derived partially from the positive feedback caused by the changed sea surface temperature due to the removal of the TP. In particular, the weakening of both the Asian monsoon and North Pacific subtropical anticyclone in association with the TP removal are shown to be greater in the context of a coupled model as compared to that in an atmosphere-only model due to the additional ocean-atmosphere feedback (Kitoh, 2004). Thus, the atmosphere-ocean feedbacks also play an important role in maintaining the inter-basin atmospheric moisture asymmetric redistribution.

\subsection{Oceanic responses and atmosphere-ocean feedbacks}

\subsubsection{Changes in freshwater and sea ice}

The above changes in the large-scale atmospheric circulation markedly decrease the total ocean density flux in the North Atlantic (Fig. 3a, brown), supporting the trend of the AMOC (Fig. 1d). The increases in both net freshwater and winddriven sea-ice expansion are responsible for the initial reduction of total ocean density flux and further induce a gradual weakening of the AMOC. In more detail, the anomalous atmospheric circulation associated with the removal of the TP transports more water vapor northward (Fig. 2d) over the North Atlantic Ocean, causing more precipitation at the beginning of NTP simulation (Fig. 3b, ca. 1101-1200 years, red 
(a) Zonal wind stress and density budget

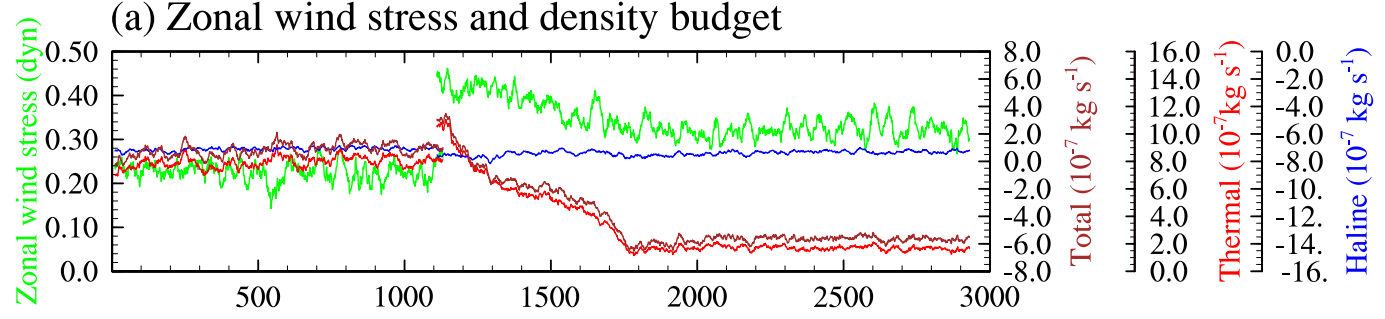

(b) Net freshwater budget

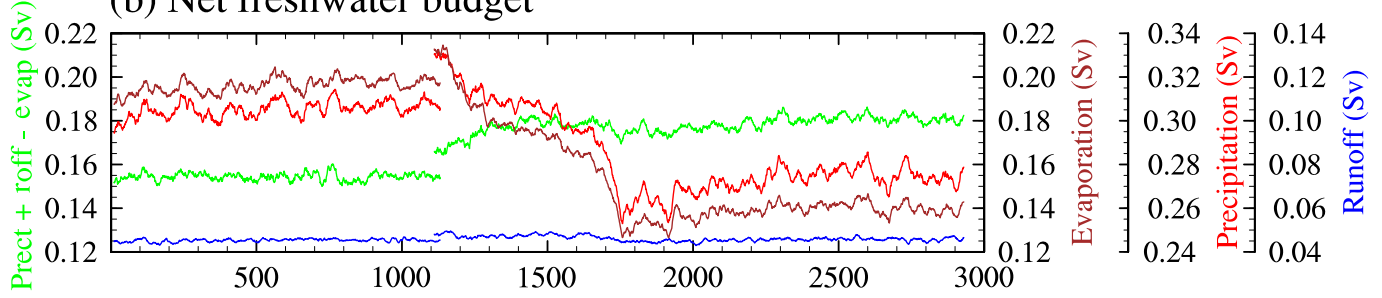

(c) Sea-ice fraction and heat budget

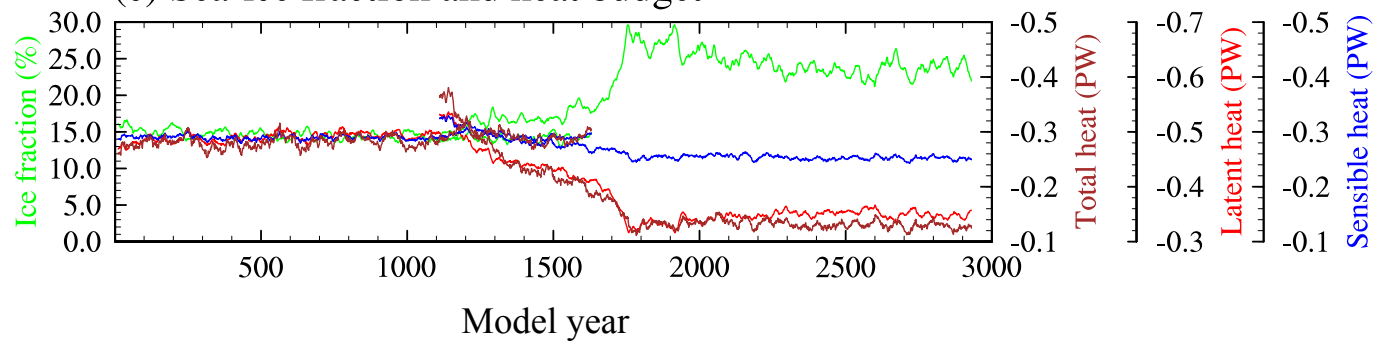

Figure 3. Regional annual mean across the North Atlantic basin at 40-70 $\mathrm{N}$ for MTP (1-1100 years) and NTP (1101-2940 years) of (a) zonal surface wind stress, total density flux, haline density flux, and thermal density flux (total density flux is decomposed into haline contribution due to freshwater flux and thermal contribution due to heat flux; Schmitt et al., 1989); (b) net freshwater, precipitation, runoff, and evaporation fluxes; (c) sea-ice fraction, total heat, sensible heat, and latent heat fluxes (units: PW, $1 \mathrm{PW}=10^{15} \mathrm{~W}$ ). For comparison purposes, all lines with common units use identical vertical scale spacing.

line). Correspondingly, the net freshwater flux (precipitation plus runoff minus evaporation) convergence into the North Atlantic basin at $40-70^{\circ} \mathrm{N}$ increases by $0.005 \mathrm{~Sv}(\sim 3 \%)$ and $0.025 \mathrm{~Sv}(\sim 16 \%)$ at the initial and final states of NTP simulations (Fig. 3b, green), respectively. It should be noted that these changes in freshwater budget in our simulations are less than approximately 0.0446 and $0.097 \mathrm{~Sv}$ of recent simulations with and without global mountains (Maffre et al., 2018), and the time for a complete collapse of the AMOC in our NTP simulation (Fig. 3b) is also longer (approximately 700 years) than for their experiments without global mountains (approximately 400 years). Such a difference should be related to the experimental design and the sensitivity of the models to freshwater forcing.

There is also a significant increase in the area-averaged sea-ice coverage over the North Atlantic through wind-driven processes (Fig. 3c, green). With the TP, the annual mean sea ice forms mainly in the northern and western regions of the subpolar North Atlantic, and it shifts southward and eastward when driven by cyclonic wind stress associated with the Icelandic Low, and melts in the Labrador Sea (subpo- lar gyre) due to a warm condition (Fig. 4a). By comparison, after removal of the TP, anomalously intensified cyclonic winds induce an anomalous eastward sea-ice velocity (Fig. 4c) and also a rapid eastward shift of the sea-ice margin (Fig. 4c). Meanwhile, the locally melted sea ice due to thermodynamics processes reduces in the southeast of Greenland (red shading, Fig. 4c), but increases in the south of Greenland (blue shading, Fig. 4c). It suggests that there is more sea ice transporting from the high latitudes into the subpolar gyre region, and the anomalous expansion of the sea-ice margin in this region primarily originates from the wind-driven eastward transportation (dynamic processes), but not the local formation (thermodynamic processes). Because of this increased sea ice through thermodynamically insulating the sea water from the freezing air, the release of sensible and latent heat into the atmosphere decreases and the density of sea water finally reduces; these processes have also been previously elucidated by Zhu et al. (2014).

Moreover, the total ocean density flux increases in the North Pacific in response to the removal of the TP. Due to the weakened Asian monsoon circulation and associated de- 
(a) MTP Atlantic sea ice

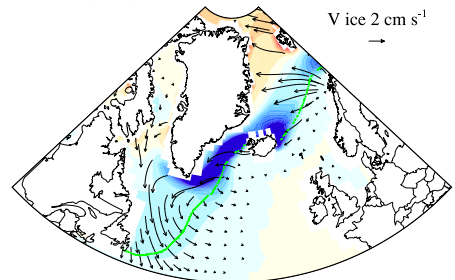

(d) MTP Pacific sea ice

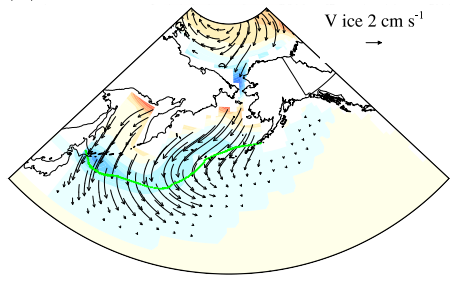

(b)NTP Atlantic sea ice

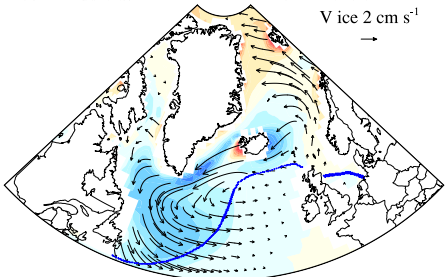

(e) NTP Pacific sea ice

(c) NTP-MTP Atlantic sea ice

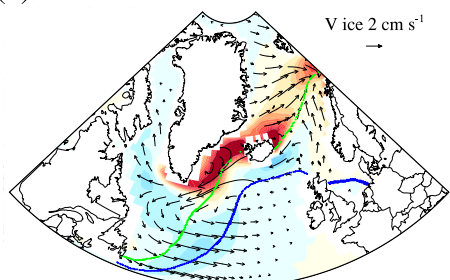

(f) NTP-MTP Pacific sea ice

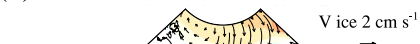

$\mathrm{V}$ ice $2 \mathrm{~cm} \mathrm{~s}^{-1}$

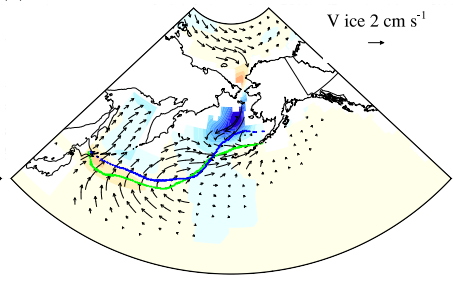

$m$ year $^{-1}$

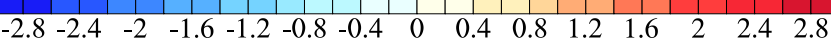

Figure 4. The North Atlantic and Pacific region features of annual mean sea-ice formation rate (shading; positive stands for formation, and negative stands for melting) and sea-ice velocity (vectors, $\mathrm{cm} \mathrm{s}^{-1}$ ) for (a, d) MTP, (b, e) NTP, and (c, f) the difference between NTP and MTP. The February sea-ice margin is indicated with dashed lines (defined as the $15 \%$ sea-ice coverage, green line for MTP, blue line for NTP).

(a) MTP total Atlantic

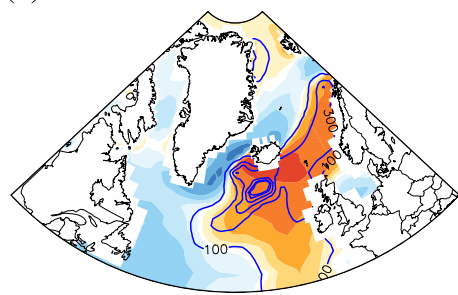

(d) NTP total Atlantic

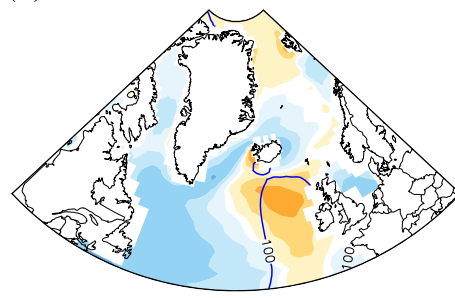

(b) MTP thermal Atlantic

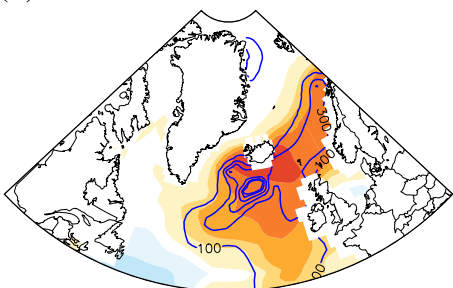

(e) NTP thermal Atlantic

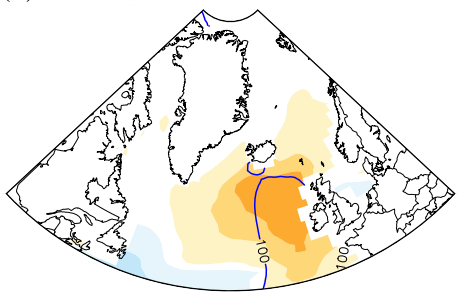

(c) MTP haline Atlantic

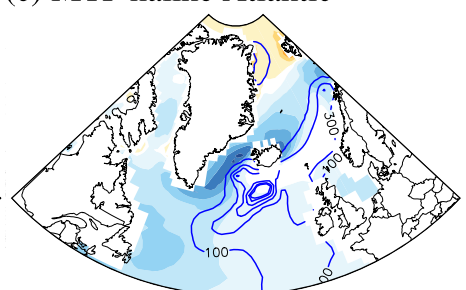

(f) NTP haline Atlantic

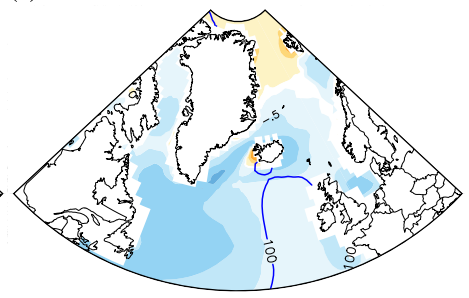

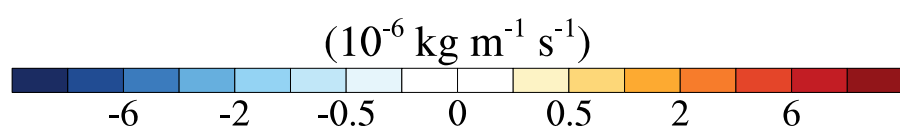

Figure 5. The North Atlantic annual mean (a, d) total density flux (shading; positive means flux makes water denser), (b, e) the thermal density flux, (c, f) the haline density flux, and the winter mixed-layer depth (blue contour, contour interval: $200 \mathrm{~m}$ ) in the MTP run (a, b, c) and $\operatorname{NTP}(\mathbf{d}, \mathbf{e}, \mathbf{f})$.

crease in rainfall and runoff after lowering the topography, the net freshwater flux received by the North Pacific decreases by $0.08(\sim 26 \%)$ and $0.12 \mathrm{~Sv}(\sim 40 \%)$ during the initial and end stages of the NTP simulation, respectively (Fig. 6b, green). This continuous negative freshwater flux forcing tends to increase density and initially leads to the formation of the North Pacific dense water, which is verified from changes in the haline density flux (Fig. 6a). Specifically, during the first 200 years of the NTP run, the haline density flux constantly produces a net positive contribution 
to the total density relative to the MTP haline term (Fig. 6a, blue line). Meanwhile, the thermal density flux remains at a lower level (Fig. 6a, ca. 1101-1300 years, red line) relative to the MTP run. Thus, it indicates that the initially increased density of the North Pacific is largely attributed to the haline density term, but not the thermal density term.

\subsubsection{Roles of the atmosphere-ocean feedbacks}

The aforementioned weakening of the AMOC due to the atmospheric processes further triggers a positive atmosphereocean feedback loop through a reduction of northward heat transport, and a subsequent decrease in sea surface temperatures, which then allow sea ice to expand, suppressing the release of evaporating latent and sensible heat, reducing the sea water density, and further weakening the AMOC, as previously shown in Jayne and Marotzke (1999) and Zhu et al. (2014). Note that the negative effect of net freshwater becomes increasingly unimportant in comparison to the heat flux feedback associated with the latent-sensible heat changes (Fig. 3a). Finally, the thermal density flux decreases by $49 \%$ relative to the MTP run, which substantially dominates the total density flux changes (Fig. 3a). To be specific, the annual mean total density flux and mixed-layer depth over the North Atlantic, especially around Iceland where the collapse of deep-water formation occurs, is dramatically decreased in NTP (Fig. 5d, the maximum mixed-layer depth is approximately $100 \mathrm{~m}$ ) in comparison to that in MTP (Fig. 5a, the maximum mixed-layer depth is approximately $900 \mathrm{~m}$ ). Moreover, this reduced total density flux over the North Atlantic is attributed more to the decreased thermal density flux associated with less latent and sensible heat release (Fig. 5e) than the changed haline density flux (Fig. 5f).

Atmosphere-ocean feedbacks also strengthen the PMOC. Due to the initial development of the PMOC mentioned in Sect. 3.1, a positive feedback (as pointed out in Warren, 1983 ) is initiated by the intensifying meridional oceanic circulation, which transports warmer subtropical water northward and leads to the buoyancy loss and evaporation increase (Fig. 6b). This feedback is also able to re-trigger PMOC enhancement. By comparison to the changes in the North Atlantic, both the regionally averaged sea-ice coverage (Fig. 6c) and February sea-ice margin (Fig. 4f) over the North Pacific experience a slightly northward retreat and have a relatively smaller effect on the simulated strengthening of the PMOC. Over a longer time, the thermal density flux, which is due to the loss of total heat, contributes more to the total density flux than the haline flux in relation to reduction in the net freshwater discharge (Fig. 6b). Spatially, both increased total density flux and mixed-layer depth in the North Pacific Ocean show opposite change characteristics from the North Atlantic (Fig. 7d). Correspondingly, in comparison to the MTP run, there is a widespread increase in the thermally induced density flux in the subpolar North Pacific in NTP (Fig. 7f), but with little spatial change in the haline density flux (Fig. 7f).
Thus, in contrast to the results shown in the North Atlantic, the increased total heat exchange between the atmosphere and ocean due to the processes of sensible and latent heat releases (Fig. 6b) ultimately becomes a dominant factor in maintaining a vigorous PMOC by controlling the increased total density flux (Fig. 6a).

\section{Conclusions and discussion}

This study investigates the effect of TP uplift on the largescale oceanic circulation using a low-resolution version of CESM. Results show that the removal of the TP initially changes the wind-driven atmospheric moisture transport process and the wind-driven sea-ice coverage expansion process, which are responsible for the initial weakening of the AMOC. Meanwhile, the suppressed monsoonal circulation in East Asia and the western Pacific marginal seas induces the decrease in rainfall and runoff and further causes the initially increased PMOC. Moreover, the positive feedback further changes the AMOC and PMOC. In particular, the AMOC weakening can further decrease the North Atlantic sea surface temperatures, ocean-atmosphere temperature contrast, evaporation, and precipitation, and subsequently increase sea-ice coverage. These processes together cause the final changes of the AMOC and PMOC (Fig. 8).

A previous study demonstrated the role of Rocky Mountain uplift on heat transport and Gulf Stream patterns in the North Atlantic (Seager et al., 2002). In this study, we focus on the most prominent long-term orogenesis occurring since the Eocene: the TP and Himalayan uplift and associated impacts on the MOC. Our results can be compared with those derived from the earlier simulations, although experimental configurations differ somewhat. It has been indicated that the removal of global mountains triggers the collapse of deep water in the North Atlantic but enables formation in the North Pacific in three different coupled models (Schmittner et al., 2011; Sinha et al., 2012; Maffre et al., 2018). The simulated weakening of the AMOC is also qualitatively consistent with recent experiments using a decreased elevation of the TP and central Asia (Fallah et al., 2016). However, only TP topography is reduced in our study, but our results are comparable with those of the earlier studies, therefore highlighting the key role that TP has played in forming the current large-scale deep oceanic circulation pattern. Nevertheless, given that all existing simulations (including ours) have used a rather coarse resolution of the coupled model configuration, it is considered that a finer-resolution model may provide a better representation of the western boundary currents and allow for a more accurate and realistic resolving of the ocean eddies, which are believed to be critically important oceanic processes that should be taken into account in the realistic simulations of the AMOC (Spence et al., 2008). In addition, the low-resolution CESM is also found to generally have a cold bias with the underestimated 
(a) Zonal wind stress and density budget

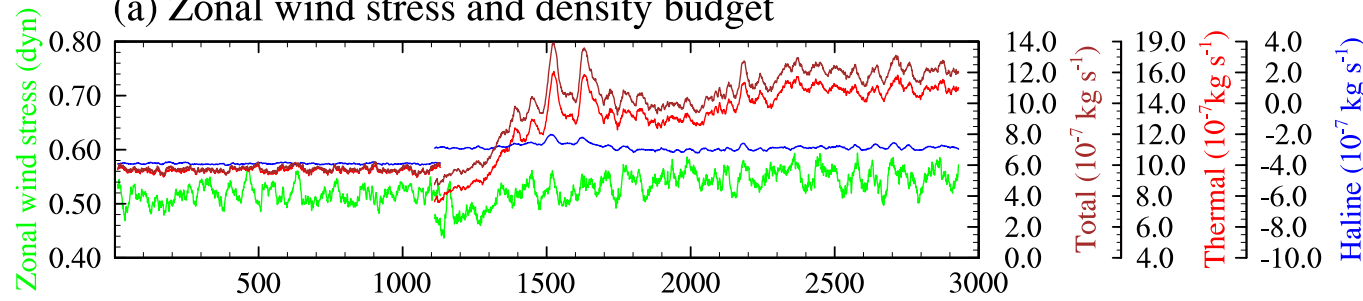

(b) Net freshwater budget

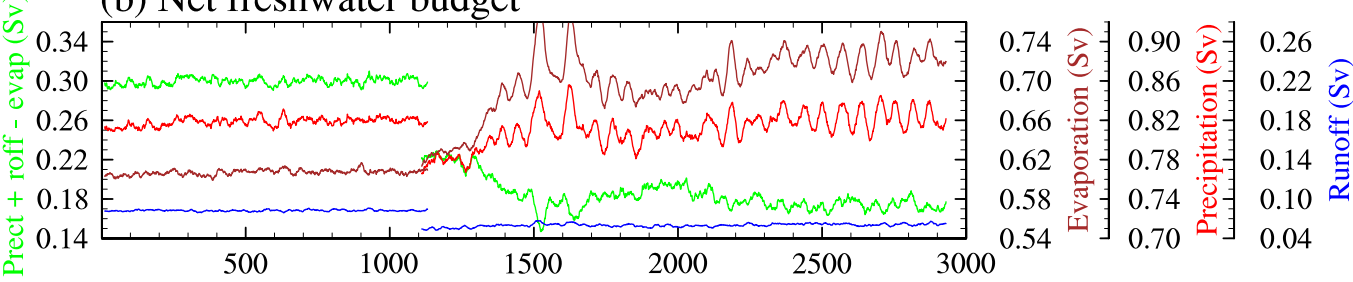

(c) Sea-ice fraction and heat budget

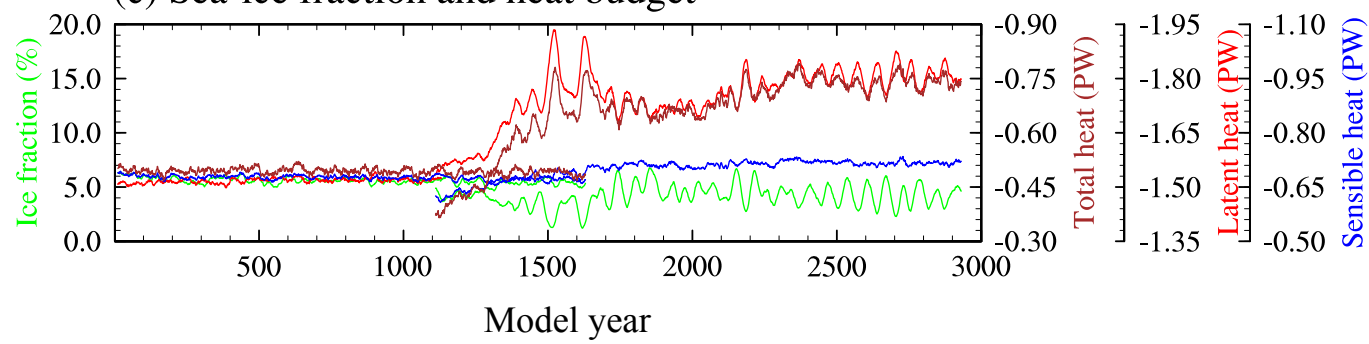

Figure 6. As in Fig. 3, but for the North Pacific basin at $30-70^{\circ} \mathrm{N}$.

(a) MTP total Pacific

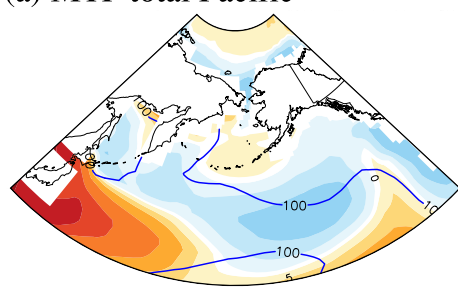

(d) NTP total Pacific (b) MTP thermal Pacific

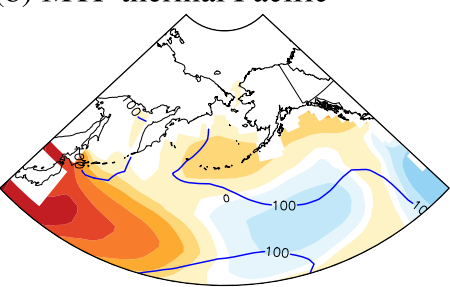

(e) NTP thermal Pacific (c) MTP haline Pacific

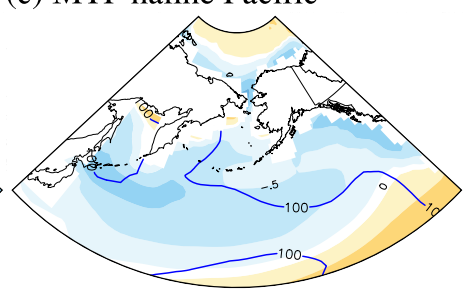

(f) NTP haline Pacific
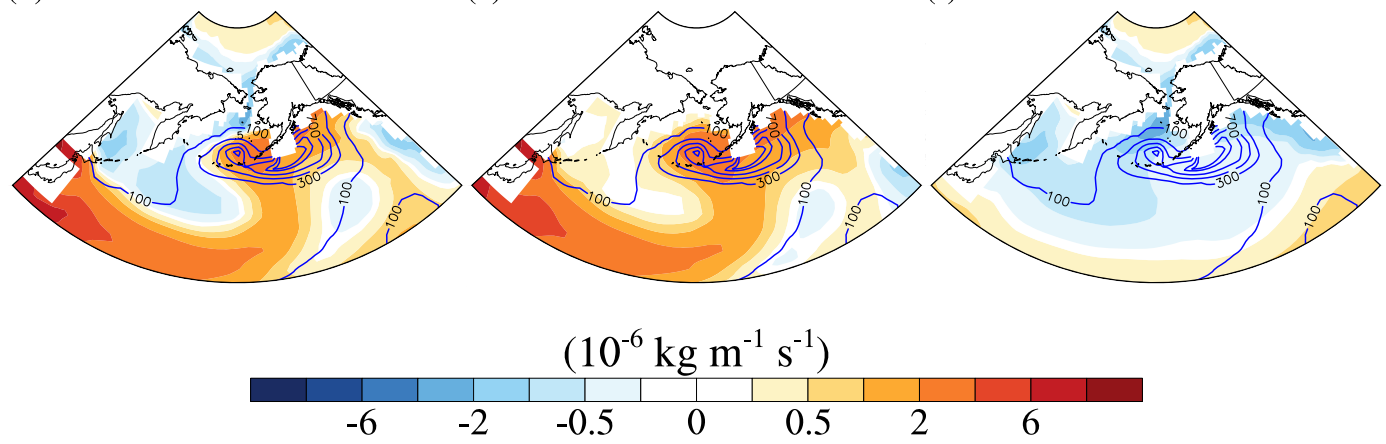

Figure 7. The same as Fig. 5, but for the North Pacific $\left(30-80^{\circ} \mathrm{N}\right)$.

ocean heat transport and excessive Arctic sea ice (Shields et al., 2012), which could potentially exert modulations on the AMOC weakening. It is thus considered that investigat- ing the response of the PMOC and AMOC to the TP uplift using an atmosphere-ocean general circulation model with a higher spatial resolution would be useful. In addition, the 


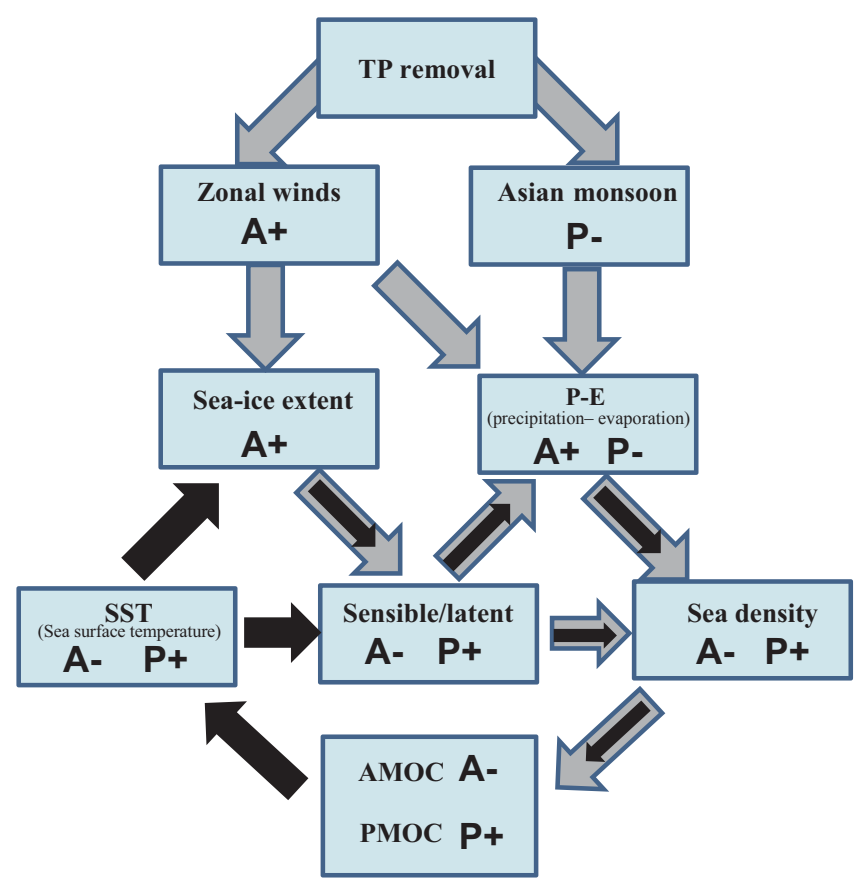

Figure 8. Schematic diagram about the influence of the removal of TP on the AMOC and PMOC. Vectors in gray denote the climate responses in relation to the increased wind-induced and decreased monsoonal-driven net precipitation-evaporation and winddriven sea-ice processes. The black vectors denote the feedback processes. The bold characters A and P stand for the physical processes occurring over the North Atlantic and Pacific, respectively.

robust changes in the AMOC and PMOC and the associated mechanisms due to the TP uplift can be evaluated through multi-model comparison.

Based on a comprehensive analysis of modern climatological data, Warren (1983) and Emile-Geay et al. (2003) hypothesized that the present MOC (mainly occurring in the Atlantic but not in the Pacific) is determined by the large mountains, namely the Himalayas and Rockies, which induce an asymmetric distribution of wind stress and moisture transport features between the Atlantic and Pacific basins. However, previous studies have also demonstrated that the asymmetric continental extents and basin widths (basin geometries) between the two basins (Weaver et al., 1999; Nilsson et al., 2013) also play a possible key role in maintaining the present-day AMOC. Our simulations support the hypothesis proposed by Warren (1983) and highlight the significant role of the TP alone in maintaining the modern AMOC. Moreover, the similar PMOC-AMOC seesaw dynamics have also been seen in simulations (Saenko et al., 2004; Chikamoto et al., 2012; Hu et al., 2012) as well as in reconstructions (Okazaki et al., 2010; Menviel et al., 2014; Freeman et al., 2015) for the last deglaciation. Such studies have also suggested that large PMOC-AMOC seesaw modulations can be triggered by slight changes in the freshwater-salinity redis- tributions between the Pacific and Atlantic. Furthermore, we provide an insight that the maintenance mechanism of the PMOC in the simulation without the TP, to some extent, is the same as the AMOC in the present day. In particular, for the current North Atlantic, there is a persistently northward movement of warm and salty water mass from the tropicalsubtropical Gulf Stream region into the North Atlantic and farther poleward into the Norwegian and Greenland seas, where it is exposed to very cold atmospheric temperatures and followed by a gradual cooling and in turn a higher density due to the release of substantial sensible and latent heat into the overlying cold atmosphere, which is the same as the PMOC, before eventually forming the North Atlantic Deep Water.

Our simulations have potential implications for understanding paleotemperature reconstructions and paleoceanographic circulation reorganization. The Earth has experienced a long-term cooling trend throughout the Cenozoic as testified by many proxies and stacked records (Zachos et al., 2001, 2008), in association with an increased Equator-topole thermal gradient. A very important contribution to understanding the large cooling during the Cenozoic has been determined as the drastic decrease in atmospheric $\mathrm{CO}_{2}$ since the Eocene (DeConto and Pollard, 2003; DeConto et al., 2008). Conversely, a study with a new database further indicated that this thermal evolution has been different among ocean basins during the Cenozoic (Cramer et al., 2009), and this differing evolutionary pattern among basins is largely related to the large-scale ocean dynamics and tectonic events (Zhang et al., 2011). Moreover, epsilon-neodymium (eps$\mathrm{Nd}$ ) isotopes in the deep Pacific suggest that the North Pacific was characterized by vigorous deep-water formation during ca. 65-40 Ma (Thomas, 2004). Other new eps-Nd records also confirm that the overturning circulation was already established in the high-latitude North Pacific prior to $40 \mathrm{Ma}$ (Hague et al., 2012; Thomas et al., 2014). Comparatively, a modern-like bipolar oceanic circulation, characterized by two branches of deep-water formation in the Southern Ocean and the North Atlantic, began in the late Eocene $(\sim 38.5 \mathrm{Ma})$ in relation to the effect of Southern Ocean gateway openings (Borrelli et al., 2014). Several records also support that the onset of the present AMOC state began at the EoceneOligocene transition $(\sim 34 \mathrm{Ma})$ in association with the tectonic deepening of the Greenland-Norwegian seas (Wright and Miller, 1993; Davies et al., 2001; Via and Thomas, 2006). However, it is likely that the intermittent Cenozoic uplift of the TP reached a certain height by the early Oligocene, as shown in geologic evidences (Dupont-Nivet et al., 2008; Wang et al., 2008). Our own contribution demonstrates that the major uplift occurring during this period was also an important player in climate changes via hydrologic and ocean dynamics changes. Indeed, we pinpoint the drastic effect of TP uplift alone on the distribution of the northern hemispheric MOCs and potentially provide clues for proxy record interpretation. 
Finally, this simulation is performed with the constant atmospheric $\mathrm{CO}_{2}$ concentrations at the preindustrial level, whereas it was higher during the uplift phase in the real world. In the context of past warm world, such as the late Eocene, the climate conditions are accompanied by high atmospheric $\mathrm{CO}_{2}$ concentration, limited sea-ice extent, and significantly modified land-sea distribution. Under these warmer boundary conditions, the responses of AMOC to the TP-induced freshwater forcing may be very different from the modern conditions (e.g., Vavrus and Kutzbach, 2002). Therefore, it will be necessary to perform further numerical experiments with more realistic boundary conditions to accurately investigate the contribution of the TP uplift on the oceanic circulation and therefore to be able to compare with data reconstructions.

Data availability. The model output data used in the figures are provided in the Supplement.

Supplement. The supplement related to this article is available online at: https://doi.org/10.5194/cp-14-751-2018-supplement.

Competing interests. The authors declare that they have no conflict of interest.

Acknowledgements. We sincerely thank the two anonymous reviewers for their insightful comments and suggestions to improve this paper. We also thank Jiang Zhu for discussions and technical support during the writing of the paper. This work was supported by the National Natural Science Foundation of China (41421004, 41572159, and 41625018).

Edited by: Arne Winguth

Reviewed by: two anonymous referees

\section{References}

Abe, M., Kitoh, A., and Yasunari, T.: An evolution of the Asian summer monsoon associated with mountain uplift-simulation with the MRI atmosphere-ocean coupled GCM, J. Meteorol. Soc. Jpn., 81, 909-933, 2003.

An, Z., Kutzbach, J. E., Prell, W. L., and Porter, S. C.: Evolution of Asian monsoons and phased uplift of the Himalaya-Tibetan plateau since Late Miocene times, Nature, 411, 62-66, 2001.

Bolin, B.: On the influence of the earth's orography on the general character of the westerlies, Tellus, 2, 184-195, 1950.

Borrelli, C., Cramer, B. S., and Katz, M. E.: Bipolar Atlantic deepwater circulation in the middle-late Eocene: Effects of southern ocean gateway openings, Paleoceanography, 29, 308-327, 2014.

Botsyun, S., Sepulchre, P., Risi, C., and Donnadieu, Y.: Impacts of Tibetan Plateau uplift on atmospheric dynamics and associated precipitation $\delta^{18} \mathrm{O}$, Clim. Past, 12, 1401-1420, https://doi.org/10.5194/cp-12-1401-2016, 2016.
Broccoli, A. J. and Manabe, S.: The effects of orography on midlatitude northern hemisphere dry climates, J. Clim., 5, 1181-1201, 1992.

Chikamoto, M. O., Menviel, L., Abe-Ouchi, A., Ohgaito, R., Timmermann, A., Okazaki, Y., Harada, N., Oka, A., and Mouchet, A.: Variability in North Pacific intermediate and deep water ventilation during Heinrich events in two coupled climate models, Deep-Sea Res. Pt. II, 61-64, 114-126, 2012.

Cramer, B. S., Toggweiler, J. R., Wright, J. D., Katz, M. E., and Miller, K. G.: Ocean overturning since the Late Cretaceous: Inferences from a new benthic foraminiferal isotope compilation, Paleoceanography, 24, PA4216, https://doi.org/10.1029/2008PA001683, 2009.

Cunningham, S. A., Kanzow, T., Rayner, D., Baringer, M. O., Johns, W. E., Marotzke, J., Longworth, H. R., Grant, E. M., Hirschi, J. J.-M., Beal, L. M., Meinen, C. S., and Bryden, H. L.: Temporal variability of the Atlantic meridional overturning circulation at $26.5^{\circ} \mathrm{N}$, Science, 317, 935-938, https://doi.org/10.1126/science.1141304, 2007.

Davies, R., Cartwright, J., Pike, J., and Line, C.: Early Oligocene initiation of North Atlantic deep water formation, Nature, 410, 917-920, 2001.

DeConto, R. M. and Pollard, D.: Rapid Cenozoic glaciation of Antarctica induced by declining atmospheric $\mathrm{CO}_{2}$, Nature, 421, 245-249, 2003.

DeConto, R. M., Pollard, D., Wilson, P. A., Pälike, H., Lear, C., and Pagani, M.: Thresholds for Cenozoic bipolar glaciation, Nature, 455, 652-657, 2008.

Dupont-Nivet, G., Hoorn, C., and Konert, M.: Tibetan uplift prior to the Eocene-Oligocene climate transition: Evidence from pollen analysis of the Xining Basin, Geology, 36, 987-990, 2008.

Emile-Geay, J., Cane, M. A., Naik, N., Seager, R., Clement, A. C., and van Geen, A.: Warren revisited: Atmospheric freshwater fluxes and "Why is no deep water formed in the North Pacific", J. Geophys. Res., 108, 3178, https://doi.org/10.1029/2001JC001058, 2003.

Fallah, B., Cubasch, U., Prömmel, K., and Sodoudi, S.: A numerical model study on the behaviour of Asian summer monsoon and AMOC due to orographic forcing of Tibetan Plateau, Clim. Dynam., 47, 1485-1495, 2016.

Feng, R. and Poulsen, C. J.: Andean elevation control on tropical Pacific climate and ENSO, Paleoceanography, 29, 795-809, 2014.

Freeman, E., Skinner, L. C., Tisserand, A., Dokken, T., Timmermann, A., Menviel, L., and Friedrich, T.: An Atlantic-Pacific ventilation seesaw across the last deglaciation, Earth Planet. Sc. Lett., 424, 237-244, 2015.

Gent, P. R., Danabasoglu, G., Donner, L. J., Holland, M. M., Hunke, E. C., Jayne, S. R., Lawrence, D. M., Neale, R. B., Rasch, P. J., Vertenstein, M., Worley, P. H., Yang, Z. L., and Zhang, M.: The Community Climate System Model version 4, J. Clim., 24, 4973-4991, https://doi.org/10.1175/2011JCLI4083.1, 2011.

Hague, A. M., Thomas, D. J., Huber, M., Korty, R., Woodard, S. C., and Jones, B. L.: Convection of North Pacific deep water during the early Cenozoic, Geology, 40, 527-530, 2012.

Holland, M. M., Bailey, D. A., Briegleb, B. P., Light, B., and Hunke, E.: Improved sea ice shortwave radiation physics in CCSM4: The impact of melt ponds and black carbon, J. Clim., 25, 1413-1430, 2012. 
Hu, A., Meehl, G. A., Han, W., Timmermann, A., Otto-Bliesner, B., Liu, Z., Washington, W. M., Large, W., Abe-Ouchi, A., and Kimoto, M.: Role of the Bering Strait on the hysteresis of the ocean conveyor belt circulation and glacial climate stability, $\mathrm{P}$. Natl. Acad. Sci. USA, 109, 6417-6422, 2012.

Jayne, S. R. and Marotzke, J.: A destabilizing thermohaline circulation-atmosphere-sea ice feedback, J. Clim., 12, 642-651, 1999.

Jiang, D., Ding, Z. L., Drange, H., and Gao, Y.: Sensitivity of East Asian climate to the progressive uplift and expansion of the Tibetan Plateau under the mid-Pliocene boundary conditions, Adv. Atmos. Sci., 25, 709-722, 2008.

Kitoh, A.: Effects of mountain uplift on East Asian summer climate investigated by a coupled atmosphere-ocean GCM, J. Clim., 17, 783-802, 2004.

Kutzbach, J. E., Prell, W. L., and Ruddiman, W. F.: Sensitivity of Eurasian climate to surface uplift of the Tibetan Plateau, J. Geol., 101, 177-190, 1993.

Liu, X. and Yin, Z.-Y.: Sensitivity of East Asian monsoon climate to the uplift of the Tibetan Plateau, Palaeogeogr. Palaeocl., 183, 223-245, 2002

Maffre, P., Ladant, J. B., Donnadieu, Y., Sepulchre, P., and Goddéris, Y.: The influence of orography on modern ocean circulation, Clim. Dynam., 50, 1277-1289, https://doi.org/10.1007/s00382-017-3683-0, 2018.

Menviel, L., England, M. H., Meissner, K. J., Mouchet, A., and Yu, J.: Atlantic-Pacific seesaw and its role in outgassing $\mathrm{CO}_{2}$ during Heinrich events, Paleoceanography, 29, 58-70, 2014.

Molnar, P., Boos, W. R., and Battisti, D. S.: Orographic controls on climate and paleoclimate of Asia: Thermal and mechanical roles for the Tibetan Plateau, Annu. Rev. Earth. Pl. Sc., 38, 77-102, 2010.

Nilsson, J., Langen, P., Ferreira, D., and Marshall, J.: Ocean basin geometry and the salinification of the Atlantic Ocean, J. Clim., 26, 6163-6184, 2013.

Okajima, H. and Xie, S. P.: Orographic effects on the northwestern Pacific monsoon: Role of air-sea interaction, Geophys. Res. Lett., 34, L21708, https://doi.org/10.1029/2007GL032206, 2007.

Okazaki, Y., Timmermann, A., Menviel, L., Harada, N., Abe-Ouchi, A., Chikamoto, M. O., Mouchet, A., and Asahi, H.: Deepwater formation in the North Pacific during the last glacial termination, Science, 329, 200-204, 2010.

Palmer, T. N., Shutts, G. J., and Swinbank, R.: Alleviation of a systematic westerly bias in general circulation and numerical weather prediction models through an orographic gravity wave drag parametrization, Q. J. Roy. Meteor. Soc., 112, 1001-1039, 1986.

Ramstein, G., Fluteau, F., Besse, J., and Joussaume, S.: Effect of orogeny, plate motion and land-sea distribution on Eurasian climate change over the past 30 million years, Nature, 386, 788795, 1997.

Rind, D., Russell, G., and Ruddiman, W. F.: The effects of uplift on Ocean-Atmosphere, in: Tectonic Uplift and Climate Change,edited by: Ruddiman, W. F., Plenum Press, New York, 123-147, 1997.

Rodwell, M. J. and Hoskins, B. J.: Subtropical anticyclones and summer monsoons, J. Clim., 14, 3192-3211, 2001.

Ruddiman, W. F. and Kutzbach, J. E.: Forcing of Late Cenozoic northern hemisphere climate by plateau uplift in southern Asia and the American West, J. Geophys. Res., 94, 18409-18427, 1989.

Saenko, O. A., Schmittner, A., and Weaver, A. J.: The AtlanticPacific seesaw, J. Clim., 17, 2033-2038, 2004.

Schmitt, R. W., Bogden, P. S., and Dorman, C. E.: Evaporation minus precipitation and density fluxes for the North Atlantic, J. Phys. Oceanogr., 19, 1208-1221, 1989.

Schmittner, A., Silva, T. A. M., Fraedrich, K., Kirk, E., and Lunkeit, F.: Effects of mountains and ice sheets on global ocean circulation, J. Clim., 24, 2814-2829, 2011.

Seager, R., Battisti, D. S., Yin, J., Gordon, N., Naik, N., Clement, A. C., and Cane, M. A.: Is the Gulf Stream responsible for Europe's mild winters?, Q. J. Roy. Meteor. Soc., 128, 2563-2586, 2002.

Sepulchre, P., Sloan, L. C., Snyder, M., and Fiechter, J.: Impacts of Andean uplift on the Humboldt Current system: A climate model sensitivity study, Paleoceanography, 24, PA4215, https://doi.org/10.1029/2008PA001668, 2009.

Shields, C. A., Bailey, D. A., Danabasoglu, G., Jochum, M., Kiehl, J. T., Levis, S., and Park, S.: The low-resolution CCSM4, J. Clim., 25, 3993-4014, 2012.

Sinha, B., Blaker, A. T., Hirschi, J., Bonham, S., Brand, M., Josey, S., Smith, R. S., and Marotzke, J.: Mountain ranges favour vigorous Atlantic meridional overturning, Geophys. Res. Lett., 39, L02705, https://doi.org/10.1029/2011GL050485, 2012.

Spence, J., Eby, M., and Weaver, A.: The sensitivity of the Atlantic meridional overturning circulation to freshwater forcing at eddypermitting resolutions, J. Clim., 21, 2697-2710, 2008.

Thomas, D. J.: Evidence for deep-water production in the North Pacific Ocean during the early Cenozoic warm interval, Nature, 430, 65-68, 2004.

Thomas, D. J., Korty, R., Huber, M., Schubert, J. A., and Haines, B.: Nd isotopic structure of the Pacific Ocean 70-30 Ma and numerical evidence for vigorous ocean circulation and ocean heat transport in a greenhouse world, Paleoceanography, 29, 454-469, 2014.

Vavrus, S. and Kutzbach, J. E.: Sensitivity of the thermohaline circulation to increased $\mathrm{CO}_{2}$ and lowered topography, Geophys Res. Lett., 29, 1546, https://doi.org/10.1029/2002GL014814, 2002.

Via, R. K. and Thomas, D. J.: Evolution of Atlantic thermohaline circulation: Early Oligocene onset of deep-water production in the North Atlantic, Geology, 34, 441-444, 2006.

Wang, C., Zhao, X., Liu, Z., Lippert, P. C., Graham, S. A., Coe, R. S., Yi, H., Zhu, L., Liu, S., and Li, Y.: Constraints on the early uplift history of the Tibetan Plateau, P. Natl. Acad. Sci. USA, 105, 4987-4992, 2008.

Warren, B. A.: Why is no deep water formed in the North Pacific?, J. Mar. Res., 41, 327-347, 1983.

Weaver, A. J., Bitz, C. M., Fanning, A. F., and Holland, M. M.: Thermohaline circulation: High-latitude phenomena and the difference between the Pacific and Atlantic, Annu. Rev. Earth. Pl. Sc., 27, 231-285, 1999.

Wright, J. D. and Miller, K. G.: Southern ocean influences on late Eocene to Miocene deepwater circulation, in: The Antarctic Paleoenvironment: A perspective on global change part two, edited by: Kennett, J. P. and Warnke, D. A., American Geophysical Union, Washington, 1-25, 1993. 
Zachos, J., Pagani, M., Sloan, L., Thomas, E., and Billups, K.: Trends, rhythms, and aberrations in global climate $65 \mathrm{Ma}$ to present, Science, 292, 686-693, 2001.

Zachos, J. C., Dickens, G. R., and Zeebe, R. E.: An early Cenozoic perspective on greenhouse warming and carbon-cycle dynamics, Nature, 451, 279-283, 2008.
Zhang, R., Jiang, D., Zhang, Z., and Yu, E.: The impact of regional uplift of the Tibetan Plateau on the Asian monsoon climate, Palaeogeogr. Palaeocl., 417, 137-150, 2015.

Zhang, Z., Nisancioglu, K. H., Flatøy, F., Bentsen, M., Bethke, I., and Wang, H.: Tropical seaways played a more important role than high latitude seaways in Cenozoic cooling, Clim. Past, 7, 801-813, https://doi.org/10.5194/cp-7-801-2011, 2011.

Zhu, J., Liu, Z., Zhang, X., Eisenman, I., and Liu, W.: Linear weakening of the AMOC in response to receding glacial ice sheets in CCSM3, Geophys. Res. Lett., 41, 6252-6258, 2014. 